\title{
Association of depression and resilience with fertility quality of life among patients presenting to the infertility centre for treatment in Karachi, Pakistan
}

\author{
Shireen Shehzad Bhamani ${ }^{1}$, Nida Zahid ${ }^{2}{ }^{*}$, Wajeeha Zahid ${ }^{3}$, Salima Farooq ${ }^{1}$, Saima Sachwani ${ }^{1}$,
} Marilyn Chapman ${ }^{4}$ and Nargis Asad ${ }^{5}$

\begin{abstract}
Background: In Pakistan there is a dire need to explore the quality of life in infertile males and females and its undesirable psychological outcomes. This, study aimed to compare the quality of life (QoL) of males and females visiting an infertility centre for treatment and to assess its association with resilience, depression, and other sociodemographic factors.
\end{abstract}

Methods: An Analytical Cross-Sectional study was conducted amongst infertile males and females at the Australian Concept Infertility Medical Centre (ACIMC), Karachi, Pakistan. The non-probability (purposive) sampling strategy was used to recruit the participants. The sample size was 668. Data was analysed using STATA version 12. FertiQoL tool, Beck II Depression Inventory Tool and Resilience Scale 14 (RS-14) were used for assessing the quality of life, depression and resilience respectively of infertile patients.

Results: Total 668 infertile patients, 334 males and 334 females participated in the study. The mean age was $35.53 \pm 6.72$, among males, and $30.87 \pm 6.12$ among females. The mean resilience scores were significantly higher among males, (77.64 \pm 8.56), as compared to females $(76.19 \pm 8.69)(95 \% \mathrm{Cl} ;-2.757,-0.1347)$. However, a significantly higher proportion of females were depressed (13.8\%) as compared to males (6\%). The mean QoL scores for the general health domain, emotional domain, mind and body domain, and relational domain, and the total QoL were significantly higher in males as compared to females ( $p$ value< 0.001 ); however, QoL for the social domain was not significantly different in both the groups. On multivariable linear regression resilience and depression among males had a significant association with QoL, after adjusting for the covariates educational status, monthly income, and number of friends. Similar association was observed among females after adjusting for the covariate monthly income only.

Conclusion: Fertility related QoL of men and women has a significant association with no formal education, number of friends, income, depression and resilience. Therefore, health care professionals in the field of infertility must be adequately trained to respond to the needs of individuals going through these psychological problems.

Keywords: Quality of life, Infertility, Gender, Resilience, Depression

\footnotetext{
* Correspondence: nida.zahid@aku.edu

${ }^{2}$ Department of Surgery, Aga Khan University, Stadium Road, Karachi 74800

Pakistan

Full list of author information is available at the end of the article
}

C C The Author(s). 2020 Open Access This article is licensed under a Creative Commons Attribution 4.0 International License, which permits use, sharing, adaptation, distribution and reproduction in any medium or format, as long as you give appropriate credit to the original author(s) and the source, provide a link to the Creative Commons licence, and indicate if changes were made. The images or other third party material in this article are included in the article's Creative Commons licence, unless indicated otherwise in a credit line to the material. If material is not included in the article's Creative Commons licence and your intended use is not permitted by statutory regulation or exceeds the permitted use, you will need to obtain permission directly from the copyright holder. To view a copy of this licence, visit http://creativecommons.org/licenses/by/4.0/. The Creative Commons Public Domain Dedication waiver (http://creativecommons.org/publicdomain/zero/1.0/) applies to the data made available in this article, unless otherwise stated in a credit line to the data. 


\section{Background}

Worldwide, infertility is recognized as a public health issue affecting the reproductive health of both genders [1]. An estimated 60 to 80 million couples suffer from infertility $[2,3]$. Infertility is a devastating experience for both the genders [4]. It can lead to marital conflict, hopelessness, guilt, shame, worthlessness, anxiety, depression, social isolation, sexual dysfunction, and decreased sexual self-esteem $[5,6]$.

Studies conducted in South Asian low and middle income countries (LMIC) report that 35 to $50 \%$ infertility is due to "male factor" infertility [7, 8], but, unfortunately social and cultural factors influence the perception of the society. In a patriarchal society like ours, child bearing inability is often attributed to female partners solely who suffer humiliation, and discrimination [1, 9-12].

Consequently, infertile women are omitted from social and traditional rituals [13], they are abused physically, emotionally, and verbally, and often end up getting divorced $[12,13]$. Thus, women who are blamed for childlessness suffer from personal grief, frustration, poor mental health and social dis-functioning which leads to negative impact on their psychological health [14-17].

Fertility also affects an individual's quality of life (QoL). The World Health Organization (WHO) [18] defines QoL as an 'individuals' perceptions of their position in life in the context of the culture and value systems in which they live and in relation to their goals, expectations, standards, and concerns" Several studies have identified that infertility can lead to poorer QoL $[11,19,20]$. However, depression, anxiety, suicidal ideation, and poor quality of life are exhibited more in infertile women as compared to infertile men [11, 13]. Studies from India, Italy, China, and Iran indicate that infertility in female partners has negative impact on their marital life $[6,11,21]$.

However, studies from Bangladesh and India suggest that infertile males are also stigmatised, socially disgraced, and their manhood is questioned, resulting in their reluctance to seek treatment [22, 23].. Although the psychological burden due to infertility is high, there is inconsistency in the reported literature [15], as not all couples report being socially distressed; their own resilience and social support seem to play a vital role in their emotional stability [24].

Resilience can act as a buffer against the negative psychological impact of infertility and help develop psychological tolerance. Individuals having resilience have high self-esteem, optimism, self-confidence, problem solving abilities, and life satisfaction. Thus, resilience is, apparently, the key to improving the QoL among infertile males and females $[15,20]$.. Therefore, there is dire need to explore the quality of life of infertile males and females from the cultural context of Pakistan and to explore its undesirable psychological outcomes. Moreover, it is also imperative to explore the coping mechanisms among infertile patients, which can ultimately prevent them from developing mental illnesses. Thus, in the light of literature, the objectives of this study were:

1 To compare the QoL of infertile males and females presenting at the infertility centre for treatment.

2 To assess its association of QoL with resilience, depression, and other socio-demographic factors in males and females presenting at the infertility center for treatment.

\section{Methods}

An analytical cross sectional study was conducted, at the Australian Concept Infertility Medical Centre (ACIMC), Karachi, Pakistan. The rationale behind the selection of this study Centre was that ACIMC is the only Centre in Karachi having the maximum flow of infertile couples seeking infertility treatment, as compared to the other infertility Centres. The additional benefit of selecting this Centre was that it had representation from all ethnic and socio-economic groups, as infertile couples are referred here from the seven sub branches of the Centre located in different provinces of Pakistan; moreover, the Angel Trust caters to the needs of the non-affording.

All Pakistani infertile men and women seeking fertility treatment, and who gave written consent, were included in this study. Patients with any known case of psychiatric illness were excluded. Our national language is Urdu which is spoken by all the ethnicities along with their own regional language. However, we excluded those who could not converse in the Urdu language because our questionnaire was in Urdu.

Purposive sampling technique was employed for selecting the participants. The infertile males and females who were receiving treatment for infertility at AIMC as per their scheduled appointment were approached by the trained data collector. The participants were screened for eligibility and those who gave written consent for participation, were enrolled in the study. This study was the secondary objective of our original project, whose primary objective was to determine the association of marital maladjustment with quality of life, depression, and resilience among infertile couples. Thus, the sample size $(n=668)$ for this study was achieved on the basis of our primary objective (paper in press), considering $80 \%$ power, significance level $5 \%$, attrition rate $10 \%$, and the anticipated odds ratio of 2 [10, 15, 25-29].

\section{Outcome variable}

\section{Quality of life}

The FertiQoL tool was used to assess the quality of life of infertile patients. This tool was validated in Urdu in 
our previous study (paper in press). The FertiQoL questionnaire is a self-reporting questionnaire, [30] specifically designed by experts from the European Society of Human Reproduction and Embryology (ESHRE) and the American Society of Reproductive Medicine (ASRM) to assess the Quality of Life of infertile patients.. It comprises of two modules: Core FertiQoL and Treatment FertiQoL module. The Core FertiQoL consists of 24 items, categorized into four domains: emotional, cognitive and physical (marked as mind/body), relational, and social. The Treatment FertiQoL module, is an optional treatment module, consists of 10 items, which are further categorized into two domains: environment and tolerability for the treatment for infertility. The scale ranges from 0 to 4 , and a higher score indicates better QoL.

\section{Independent variables \\ Depression}

Depression was assessed through the Urdu version of the Beck II Depression Inventory Tool, (the content and face validity was performed) $[25,31,32]$. This tool covers a broad behavioural spectrum and is easy to understand therefore is widely used in Pakistan. It is a 21 item selfreporting measure of depressive symptomatology, which includes: sadness, pessimism, past failure, loss of pleasure, guilty feelings, punishment feelings, self-dislike, selfcriticalness, suicidal thoughts or wishes, crying, agitation, loss of interest, indecisiveness, worthlessness, loss of energy, changes in sleeping pattern, irritability, changes in appetite, concentration difficulty, tiredness or fatigue, and loss of interest in sex. The recommended cut off score for depression is 14 . The higher the score the greater the severity of depressive symptoms. This tool has been widely used in Pakistan. Many AKU initiated research projects have used the tool because it covers a broad behavioural spectrum and is easy to understand.

\section{Resilience}

Resilience, is the ability to rebound or spring back, in other words the power to resume to its original shape or position after compression or bending [33]. Data for resilience was collected through the validated Urdu version of Resilience Scale 14 (RS-14) [31]. Participants were considered resilient, if they scored atleast 73 on the RS-14 scale.

\section{Socio-demographic factors}

A structured questionnaire was administered to obtain preliminary information about participants age, education, language, number of family members, type of marriage, its duration, personal health; reproductive history, (including number of miscarriages, alive/dead children, age of last child for secondary infertility cases), cause of infertility ("male factor"/female), extra marital affairs or/ and multiple marriages; and social and religious support mechanisms.

\section{Ethical approval}

The ethical approval (ERC No. 4615-SON-ERC-17) was received from the Institutional Ethical Review Committee, AKU; and approval was also sought from the participating study site, AIMC. A written informed consent form, signed by the study participants, was obtained before the initiation of this study. We assured complete confidentiality of the study participants. The data was only accessible to the researchers and the responses were reported in group form; no individual case was identified.

\section{Plan of analysis/data management}

The data was double entered in Microsoft access software by trained data entry operators. The overall quality of the study was maintained through random spotchecks. The data base was pass word protected and was only accessible by the research group. Missing data was dealt by imputation. Statistical analysis was done on STATA version 12. Descriptive analyses for quantitative variables were reported as mean $\pm \mathrm{SD} /$ median (IQR) and were assessed through the $t$ test or the Mann Whitney test, as deemed appropriate. Frequency and percentages were reported for qualitative variables and were assessed by the chi square test or the fisher exact test, as deemed appropriate. Unadjusted and adjusted beta coefficients, along with their 95\% CI, were reported using linear regression analysis, to determine the association of resilience, depression, and other factors with the total QoL of males and females, by. All plausible interactions and confounders were assessed. A $p$ - value of $<0.05$ was considered as significant.

\section{Results}

In all, 334 males and 334 females, presenting at the infertility centre for treatment, were enrolled. 584 (87.4\%) had primary infertility and $84 \%(12.6 \%)$ had secondary infertility. A higher proportion 148 (22\%) had male factor infertility, 130 (19.5\%) had female factor infertility, $10(1.5 \%)$ had both male and female factor infertility, and $56.9 \%$ didnot know the cause.

\section{Socio-demographic factors of the study participants}

Table 1 is divided into 3 sections: Demographic factors, Socio-economic factors, and Social religious network of the infertile patients presenting at the infertility centre.

Section A of Table 1 describes the demographic factors of the study participants. The mean age was significantly higher among males, $35.53 \pm 6.72$, as compared to females, $30.87 \pm 6.12$ ( $p$ value 0.001 ). A higher proportion of males (93.1\%) had formal education as compared to their counterparts $(84.19 \%)(p$-value $<0.001)$, with 
Table 1 Socio-demographic factors of the study participants presenting to the infertility Centre

\begin{tabular}{|c|c|c|c|}
\hline & Male $(n=334)$ & Female $(n=334)$ & $P$ value \\
\hline \multicolumn{4}{|l|}{ A. Demographics } \\
\hline \multicolumn{4}{|l|}{ Age (in years) } \\
\hline Mean \pm SD & $35.53 \pm 6.72$ & $30.87 \pm 6.12$ & $0.001^{*}$ \\
\hline \multicolumn{4}{|l|}{ Formal Education } \\
\hline Yes & $311(93.1 \%)$ & $281(84.1 \%)$ & $<0.001^{*}$ \\
\hline No & $23(6.9 \%)$ & $53(15.9 \%)$ & \\
\hline \multicolumn{4}{|l|}{ Years of education (in years) } \\
\hline Median (IQR) & $14(10-16)$ & $12(7-16)$ & $0.001^{*}$ \\
\hline \multicolumn{4}{|l|}{ Informal Education } \\
\hline Yes & $167(50.0 \%)$ & $209(62.6 \%)$ & $0.001^{*}$ \\
\hline No & $167(50.0 \%)$ & $125(37.4 \%)$ & \\
\hline \multicolumn{4}{|l|}{ Role in the family } \\
\hline Head & $156(46.7 \%)$ & $8(2.40 \%)$ & $<0.001^{*}$ \\
\hline Not Head but take part in decision & $171(51.2 \%)$ & $251(75.1 \%)$ & \\
\hline Does not take decision, only follower & $7(2.10 \%)$ & $75(22.5 \%)$ & \\
\hline \multicolumn{4}{|l|}{ First Marriage } \\
\hline Yes & $305(91.3 \%)$ & $321(96.1 \%)$ & $0.011^{*}$ \\
\hline No & $29(8.70 \%)$ & $13(3.90 \%)$ & \\
\hline \multicolumn{4}{|l|}{ B. Socioeconomic } \\
\hline \multicolumn{4}{|l|}{ Working } \\
\hline Yes & $326(97.6 \%)$ & $52(15.6 \%)$ & $<0.001^{*}$ \\
\hline No & $8(2.40 \%)$ & $282(84.4 \%)$ & \\
\hline \multicolumn{4}{|l|}{ Spouse employed } \\
\hline Yes & $50(15.0 \%)$ & $330(98.8 \%)$ & $<0.001^{*}$ \\
\hline No & $284(85.0 \%)$ & $4(1.20 \%)$ & \\
\hline $\begin{array}{l}\text { Total household income (in PKR) } \\
\text { Median (IQR) }\end{array}$ & $50,000(30000-90,000)$ & $35,000(20000-50,000)$ & $<0.001^{*}$ \\
\hline \multicolumn{4}{|l|}{ Total Monthly income (in PKR) } \\
\hline $1000-25,000$ & $61(18.4 \%)$ & $84(25.3 \%)$ & $<0.001^{*}$ \\
\hline $25,000-40,000$ & $58(17.5 \%)$ & $86(25.9 \%)$ & \\
\hline $40,000-80,000$ & $106(32.0 \%)$ & $103(31.0 \%)$ & \\
\hline $80,000-10,000,000$ & $106(32.0 \%)$ & $59(17.8 \%)$ & \\
\hline Total & 331 & 332 & \\
\hline \multicolumn{4}{|l|}{ C. Social/Religious Network } \\
\hline \multicolumn{4}{|l|}{ No of meet up with friends/week } \\
\hline$<1$ times /week & $195(58.4 \%)$ & $265(79.3 \%)$ & $<0.001^{*}$ \\
\hline 1-5 times/ week & $133(39.8 \%)$ & $49(14.7 \%)$ & \\
\hline$\geq 5$ times/week & $6(12.3 \%)$ & $6(3.40 \%)$ & \\
\hline \multicolumn{4}{|l|}{ Religious activities } \\
\hline Yes & $310(92.8 \%)$ & $331(99.1 \%)$ & $<0.001^{*}$ \\
\hline No & $24(7.20 \%)$ & $3(0.90 \%)$ & \\
\hline
\end{tabular}

*significant at $p$ value $<0.05$ by $\mathrm{t}$ test/chisquare/fisher exact test 
higher median years of education among males as compared to females. However, a higher proportion of females $(62.6 \%)$ had informal education as compared to their counterparts $(50 \%)$ ( $p$ value $=0.001)$. We also observed that a significantly higher proportion of males (46.7\%) were heads of the family as compared to females $(2.4 \%)$ ( $p$ value $<0.001$ ). Moreover, a significantly higher proportion of males $(8.7 \%)$ had more than one marriage as compared to (3.9\%) females who were previously married.

Section B of Table 1 describes the socio-economic status of the study participants. We observed that a significantly higher proportion of females $(84.4 \%)$ were not working as compared to males $(2.4 \%)$ ( $p$ value $<0.001)$. The median monthly household income reported by males was significantly higher, i.e. PKR 50,000 (30,000$90,000)$, as compared to females, PKR 35,000 (20,000$50,000)$ ( $p$ value $<0.001)$.

Section C of Table 1 presents the social/ religious network of the study participants. We observed that the males had a greater number of meet ups with their friends as compared to females ( $p$ value < 0.001). Moreover, we observed that a significantly higher proportion of females (99.1\%) were involved in religious activities as compared to males (92.8\%) ( $p$ value $<0.001)$
Resilience, depression, and QoL in infertile males and females

Table 2 shows resilience, depression, and QoL in infertile males and females. We observed that the mean resilience scores were significantly higher among males, $77.64 \pm 8.56$, as compared to females, $76.19 \pm 8.69$ with a $95 \% \mathrm{CI} ;-2.757,-0.1347$ ( $p$ value $=0.031)$. The proportion of less resilient females (29.6\%) was significantly higher than that of less resilient males (21.3\%). However, a significantly higher proportion of females were depressed (13.8\%) as compared to males (6\%). We observed that the mean QoL scores for the general health domain, emotional domain, mind and body domain, and relational domain, and the total QoL were significantly higher in males as compared to females ( $p$ value $<0.001)$; however, QoL for the social domain was not significantly different in both the groups.

\section{Univariate analysis to assess the relationship of depression, resilience, and demographic factors with the total quality of life, in males and females presenting for infertility treatment}

Table 3 presents the univariate analysis to assess the relationship of demographic factors, with the total quality of life, in males and females presenting for infertility treatment.

Table 2 Resilience, Depression and QoL among infertile males and females

\begin{tabular}{|c|c|c|c|}
\hline Resilience/Depression & Male $(n=334)$ & Female $(n=334)$ & $p$-value \\
\hline \multicolumn{4}{|l|}{ Resilience } \\
\hline Resilience (Mean \pm SD) & $77.64 \pm 8.56$ & $76.19 \pm 8.69$ & $0.031^{*}$ \\
\hline Resilience & & & $0.013^{*}$ \\
\hline$<73$ (less resilient) & $71(21.3 \%)$ & $99(29.6 \%)$ & \\
\hline$\geq 73$ (more resilient) & $263(78.7 \%)$ & $235(70.4 \%)$ & \\
\hline \multicolumn{4}{|l|}{ Depression } \\
\hline Depression (Median (IQR)) & $3.00(1.00-7.00)$ & $7.00(2.00-12.00)$ & $<0.001^{*}$ \\
\hline Depression & & & $<0.001^{*}$ \\
\hline$<17$ (not depressed) & $314(94.0 \%)$ & $288(86.2 \%)$ & \\
\hline$\geq 17$ (depressed) & $20(6.0 \%)$ & $46(13.8 \%)$ & \\
\hline \multicolumn{4}{|l|}{ Quality of life } \\
\hline $\begin{array}{l}\text { General Health } \\
\text { Mean } \pm S D\end{array}$ & $56.45 \pm 19.36$ & $48.34 \pm 11.52$ & $<0.001^{*}$ \\
\hline $\begin{array}{l}\text { Emotional Domain } \\
\text { Mean } \pm S D\end{array}$ & $82.63 \pm 13.43$ & $60.02 \pm 23.38$ & $<0.001^{*}$ \\
\hline $\begin{array}{l}\text { Mind and Body Domain } \\
\text { Mean } \pm S D\end{array}$ & $85.65 \pm 15.46$ & $55.40 \pm 23.60$ & $<0.001^{*}$ \\
\hline $\begin{array}{l}\text { Relational Domain } \\
\text { Mean } \pm S D\end{array}$ & $79.98 \pm 19.56$ & $88.76 \pm 10.60$ & $<0.001^{*}$ \\
\hline $\begin{array}{l}\text { Social Domain } \\
\text { Mean } \pm S D\end{array}$ & $78.23 \pm 13.35$ & $77.75 \pm 18.05$ & 0.696 \\
\hline $\begin{array}{l}\text { Total Qol scores } \\
\text { Mean } \pm \text { SD }\end{array}$ & $81.58 \pm 12.15$ & $70.48 \pm 15.69$ & $<0.001^{*}$ \\
\hline
\end{tabular}

*significant at $p$ value $<0.05$ by chi-square of independence/ $t$ test 
Table 3 Univariate analysis to assess relationship of demographic factors with total quality of life among males and females presenting for infertility treatment

\begin{tabular}{|c|c|c|c|c|}
\hline \multirow[t]{2}{*}{ Variables } & \multicolumn{4}{|l|}{ Univariate analysis } \\
\hline & $\begin{array}{l}\text { Males } \\
\text { Unadjusted beta } \\
\text { coefficient (SE) }\end{array}$ & $95 \% \mathrm{Cl}$ & $\begin{array}{l}\text { Females } \\
\text { Unadjusted beta } \\
\text { coefficient (SE) }\end{array}$ & $95 \% \mathrm{Cl}$ \\
\hline Age (in years) & $-0.043(0.099)$ & $-0.239,0.151$ & $-0.054(0.140)$ & $-0.331,0.221$ \\
\hline \multicolumn{5}{|l|}{ Formal Education } \\
\hline \multicolumn{5}{|l|}{ Yes (ref) } \\
\hline No & $-9.051(2.569)$ & $-14.106,-3.996^{*}$ & $-6.101(2.329)$ & $-10.683,-1.518^{*}$ \\
\hline Years of formal education (in years) & $0.269(0.070)$ & $0.131,0.407^{*}$ & $0.135(0.071)$ & $-0.004,0.275^{*}$ \\
\hline \multicolumn{5}{|l|}{ Informal Education } \\
\hline \multicolumn{5}{|l|}{ Yes (ref) } \\
\hline No & $2.345(1.319)$ & $-0.249,4.940^{*}$ & $3.113(1.768)$ & $-0.365,6.592^{*}$ \\
\hline \multicolumn{5}{|l|}{ Type of Marriage } \\
\hline \multicolumn{5}{|l|}{ Self-Choice (ref) } \\
\hline Arranged & $0.119(1.611)$ & $-3.051,3.289$ & $-6.122(2.277)$ & $-10.602,-1.642^{*}$ \\
\hline Duration of marriage (in years) & $-0.302(0.124)$ & $-0.546,-0.057^{*}$ & $0.051(0.139)$ & $-0.221,0.324$ \\
\hline \multicolumn{5}{|l|}{ Type of family } \\
\hline Extended & $2.176(1.378)$ & $-0.535,4.888^{*}$ & $2.759(1.799)$ & $-0.781,6.300^{*}$ \\
\hline \multicolumn{5}{|l|}{ Nuclear (ref) } \\
\hline \multicolumn{5}{|l|}{ Role in the family } \\
\hline \multicolumn{5}{|l|}{ Head (ref) } \\
\hline Not Head but take part in decision & $-0.449(1.340)$ & $-3.086,2.186^{*}$ & $-11.740(5.565)$ & $-22.629,-0.730$ \\
\hline Does not take decision, only follower & $-5.367(4.677)$ & $-14.568,3.833$ & $-16.373(5.763)$ & $-27.711,-5.036$ \\
\hline \multicolumn{5}{|l|}{ Type of infertility } \\
\hline Primary & $-1.585(1.976)$ & $-0.547,2.303$ & $-9.248(2.571)$ & $-14.305,-4.191^{*}$ \\
\hline Secondary (ref) & & & & \\
\hline
\end{tabular}

*significant at $\mathrm{p}$ value $<0.25$ by univariate analysis

We observed that age had a significant association with Qol of male and female infertile patients. However, male and females with no formal education had significantly lower Qol scores i.e. 9 and 6 units, respectively, as compared to those with formal education. Similarly, years of formal education significantly increased the QoL of males and females. The QoL scores of female patients who had arrange marriage was 6 units significantly lower as compared to those who had love marriage. On the other hand, there was no significant association in the type of marriage and QoL scores among males. However, there was significant negative association of duration of marriage with QoL among males, but not among females. Moreover, males and females who lived in extended families had significantly higher QoL scores as compared to those who lived in nuclear families. Furthermore, the QoL scores were significantly higher of females who were not the head of the family but took part in decision making as compared to those who did not take part in decision making. The QoL of females with primary infertility was 9 units significantly lower as compared to those with secondary infertility, however there was no significant association of QoL and type of infertility among males.

We also evaluated the relationship of socio-economic factors with mean QoL in males and females (Table 4). We did not observe any significant association of QoL with working status in males and females. However, QoL of females, working outside their house was 9 units significantly higher compared to those working from home. Moreover, the QoL was significantly lower among males and females with low total household monthly income. Furthermore, QoL of males and females who did not have a television and/or a refrigerator in their house, their own cultivated land, and a vehicle was significantly low as compared to those who had any or all of these. Additionally, the quality of life of males decreased significantly by 0.6 units with increase in number of friends; however, this did not have any significant relationship with the QoL of females. 
Table 4 Univariate analysis to assess relationship of Socioeconomic with total quality of life among males and females presenting for infertility treatment

\begin{tabular}{|c|c|c|c|c|}
\hline Variables & $\begin{array}{l}\text { Males } \\
\text { Unadjusted beta } \\
\text { coefficient (SE) }\end{array}$ & $95 \% \mathrm{Cl}$ & $\begin{array}{l}\text { Females Unadjusted beta } \\
\text { coefficient (SE) }\end{array}$ & $95 \% \mathrm{Cl}$ \\
\hline \multicolumn{5}{|l|}{ Working status } \\
\hline \multicolumn{5}{|l|}{ Yes (ref) } \\
\hline No & $-4.957(4.325)$ & $-13.467,3.5523$ & $-0.319(2.371)$ & $-4.984,4.346$ \\
\hline \multicolumn{5}{|l|}{ Work Place } \\
\hline Inside the house (ref) & - & - & - & - \\
\hline Outside the house & $-4.418(1.829)$ & $-8.016,-0.820^{*}$ & $9.143(3.908)$ & $1.288,16.997^{*}$ \\
\hline Both & $9.312(12.015)$ & $-14.325,32.950$ & $-13.706(9.972)$ & $-33.746,6.334$ \\
\hline \multicolumn{5}{|c|}{ Total Monthly income (in PKR) } \\
\hline $1000-25,000$ & $-6.385(1.921)$ & $-10.165,-2.604^{*}$ & $-8.401(2.582)$ & $-13.479,-3.322^{*}$ \\
\hline $25,000-40,000$ & $-2.255(1.952)$ & $-6.097,1.586$ & $0.009(2.569)$ & $-5.045,5.063$ \\
\hline $40,000-80,000$ & $-4.056(1.646)$ & $-7.295,-0.817^{*}$ & $2.499(2.477)$ & $-2.373,7.373$ \\
\hline $80,000-10,000,000$ (ref) & - & - & - & - \\
\hline \multicolumn{5}{|l|}{ TV in the house } \\
\hline Yes (ref) & - & - & - & - \\
\hline No & $-4.945(1.941)$ & $-8.763,-1.128^{*}$ & $-6.244(2.471)$ & $-11.161,-1.382^{*}$ \\
\hline \multicolumn{5}{|c|}{ Refrigerator in the house } \\
\hline Yes (ref) & - & - & - & \\
\hline No & $-6.655(2.106)$ & $-10.797,-2.513^{*}$ & $-10.016(2.912)$ & $-15.744,-4.287^{*}$ \\
\hline \multicolumn{5}{|l|}{ Own cultivated land } \\
\hline Yes (ref) & - & - & - & - \\
\hline No & $-4.184(1.658)$ & $-7.446,-0.923^{*}$ & $-5.092(1.954)$ & $-8.937,-1.248^{*}$ \\
\hline \multicolumn{5}{|l|}{ Own Vehicle } \\
\hline Yes (ref) & - & - & - & - \\
\hline No & $-6.914(1.575)$ & $-10.011,-3.815^{*}$ & $-6.760(1.989)$ & $-10.673,-2.847^{*}$ \\
\hline Number of friends & $-0.603(0.202)$ & $-0.1000,-0.206^{*}$ & $-0.126(0.320)$ & $-0.757,0.504$ \\
\hline
\end{tabular}

*significant at $p$ value $<0.25$ by univariate analysis

We also evaluated the relationship of resilience and depression with QoL in males and females (Table 5) and we observed that QoL of males and females who had low resilience was 12 and 13 units significantly lower, respectively, as compared to those who had higher resilience. Moreover, QoL in males and females was 21 and 22 units significantly lower, respectively, among those were depressed as compared to those who were not depressed.

Multivariable analysis to assess the relationship of depression, resilience, and demographic factors with the total quality of life, in males and females presenting for infertility treatment

Table 6 shows the multivariable analysis to assess the relationship of demographic factors, socio-economic factors, resilience, and depression with the total quality of life, in males and females presenting for infertility treatment.

We observed that among males resilience and depression had a significant association with QoL, after adjusting for the covariates educational status, monthly income, and number of friends. Males who were less resilient their QoL was 8 units significantly lower as compared to those who were more resilient. Similarly, those males who were depressed their QoL was 17 units significantly lower as compared to those who were not. Moreover, males who had no formal education their QoL was 5 units lower as compared to those who had received formal education. Males whose household monthly income was between 10,000-80,000 PKR their QoL was lower as compared to those who had an income between 80,000-10,000,000 PKR. Furthermore, males who had more friends had lower QoL scores. 
Table 5 Univariate analysis to assess relationship of Resilience and Depression with quality of life among males and females presenting for infertility treatment

\begin{tabular}{|c|c|c|c|c|}
\hline Variables & $\begin{array}{l}\text { Males } \\
\text { Unadjusted beta } \\
\text { coefficient (SE) }\end{array}$ & $95 \% \mathrm{Cl}$ & $\begin{array}{l}\text { Females } \\
\text { Unadjusted beta } \\
\text { coefficient (SE) }\end{array}$ & $95 \% \mathrm{Cl}$ \\
\hline Resilience & $0.677(0.067)$ & $0.543,0.811^{*}$ & $0.828(0.088)$ & $0.655,1.001^{*}$ \\
\hline \multicolumn{5}{|l|}{ Resilience } \\
\hline < 73 (less resilient) & $-12.018(1.479)$ & $-14.92,-9.108^{*}$ & $-13.278(1.736)$ & $-16.694,-9.863^{*}$ \\
\hline$\geq 73$ (more resilient) (ref) & - & - & - & - \\
\hline Depression & $-1.057(0.092)$ & $-1.238,-0.888^{*}$ & $-1.597(0.082)$ & $-1.758,-1.435^{*}$ \\
\hline \multicolumn{5}{|l|}{ Depression } \\
\hline$<17$ (not depressed) (ref) & - & - & - & - \\
\hline$\geq 17$ (depressed & $-21.490(2.532)$ & $-26.471,16.509^{*}$ & $-22.369(2.172)$ & $-26.642,18.095^{*}$ \\
\hline
\end{tabular}

*significant at $p$ value $<0.25$ by univariate analysis

We observed that among females resilience and depression had a significant association with QoL, after adjusting for the covariate monthly income. Females who were less resilient their QoL was 8 units lower as compared those who were more resilient. Similarly, those females who were depressed their QoL was 19 units significantly lower as compared to those who were not. Moreover, females whose household monthly income was between 10,000-25,000 PKR their QoL was 7 units significantly lower as compared to those who had an income between 80,000-10,000,000 PKR.

\section{Discussion}

This study aimed to compare the QoL of males and females presenting at the infertility centre for treatment and to assess its association with other factors.

This study showed that infertile males were more resilient than infertile females. The plausible reasons for men being more resilient than females in Pakistan would be our society norms, where men are treated as superiors and have more rights, power, and authority to take decisions.

Moreover, in a developing country like ours, that has a patriarchal and polygamous society, married women who

Table 6 Multivariable analysis to assess relationship of depression, resilience and demographic factors with total quality of life among males and females presenting for infertility treatment

\begin{tabular}{|c|c|c|c|c|}
\hline \multirow[t]{2}{*}{ Variables } & \multicolumn{4}{|l|}{ Multivariable analysis } \\
\hline & $\begin{array}{l}\text { Males } \\
\text { Adjusted Beta Coefficient (SE) }\end{array}$ & $95 \% \mathrm{Cl}$ & $\begin{array}{l}\text { Females } \\
\text { Adjusted Beta Coefficient (SE) }\end{array}$ & $95 \% \mathrm{Cl}$ \\
\hline \multicolumn{5}{|l|}{ Resilience } \\
\hline$<73$ (less resilient) & $-8.470(1.422)$ & $-11.268,-5.672^{*}$ & $-8.606(1.599)$ & $-11.753,-5.458^{*}$ \\
\hline$\geq 73$ (more resilient) (ref) & - & - & - & - \\
\hline \multicolumn{5}{|l|}{ Depression } \\
\hline$<17$ (not depressed) (ref) & - & - & - & - \\
\hline$\geq 17$ (depressed) & $-17.849(2.365)$ & $-22.503,-13.196^{*}$ & $-19.387(2.078)$ & $-23.476,-15.298^{*}$ \\
\hline \multicolumn{5}{|l|}{ Formal Education } \\
\hline Yes (ref) & - & - & NS & NS \\
\hline No & $-5.374(2.245)$ & $-9.794,-0.954^{*}$ & & \\
\hline Number of friends & $-0.554(0.172)$ & $-0.893,-0.216^{*}$ & NS & NS \\
\hline \multicolumn{5}{|c|}{ Total Monthly income (in PKR) } \\
\hline $10,000-25,000$ & $-3.551(1.687)$ & $-6.870,-0.231^{*}$ & $-7.249(2.161)$ & $-11.501,-2.996^{*}$ \\
\hline $25,000-40,000$ & $-1.793(1.670)$ & $-5.079,-1.493$ & $-2.615(2.155)$ & $-6.854,1.624$ \\
\hline $40,000-80,000$ & $-2.747(1.386)$ & $-5.474,-0.020^{*}$ & $-0.644(2.078)$ & $-3.443,4.732$ \\
\hline $80,000-10,000,000$ (ref) & - & - & - & - \\
\hline
\end{tabular}

*Significant at $p$ value $<0.05$ by multivariable analysis NS non significant 
are unable to conceive are stigmatized and blamed by their spouses and in-laws, which leads to depression among infertile females, and high prevalence of depression is significantly associated with low QoL. This finding is consistent with other studies that were carried out in Ghana, Iraq, and Germany, which also indicated that females scored high in depression. A study carried out in western Iran also found that $76 \%$ of infertile women suffered from depression, while $61.5 \%$ suffered from clinical depression [34-36]. Another study showed that prevalence of depression and anxiety in infertile women was high as compared to men [6]. Moreover, the divorce rate is twice as high amongst infertile couples and the fear of remarriage of their husbands adds to their misery [37].

Furthermore, females undergo numerous invasive procedures for infertility diagnosis and treatment, in comparison to males [21]. All these factors have a negative impact on the females, contributing to the high prevalence of depression among them. Our findings are comparable to those reported by infertile women in developing countries, including Iran, Taiwan, India, Tunisia, and China, and developed countries, like the USA, Poland, and Italy [38-44]. However, a few studies, have not found any association between QoL and depression among infertile women $[45,46]$.

In our study, the infertile females and males having higher household monthly income had a significantly better QoL in comparison to those with lower monthly income. This is comparable to the study carried out in Iran, by Namdar et al. [47], which also reported a positive association between monthly income and QoL in women. Another study conducted in Iran on infertile couples also reported a positive association, which is consistent with our findings, that higher income is associated with better QoL among the male gender [48]. Hence, this shows that financial stability can compensate for the compromised quality of life of an infertile individual. A reason for this could be that infertility treatment is expensive, therefore, individuals with financial instability possibly feel more distressed due to the high cost of the treatment, versus those who are financially stable.

In addition, our study identified that infertile females and males having higher resilience had a significantly better QoL in comparison to those with low resilience scores. Literature also portrays that resilience is positively associated with fertility QoL. Resilience also has a moderating effect on psychological stress associated with QoL ([20]. Moreover, another study also supports that resilience is a protective factor against infertility related distress and impaired quality of life for infertile couples [15].

Our study results showed that infertile males having a large circle of friends had lower QoL scores. Presumably, with more friends the infertile males may face more social pressure or a lot of probing questions, which adds to their frustration related to infertility, resulting in lower QoL scores. Literature also suggests that men have less social support and are less likely to confide in friends about infertility as compared to women [49]. On the other hand, a reason why infertile males have a growing social circle of friends could be that this serves as a diversion, or as a coping mechanism, or it provides an outlet for their emotions to overcome the feelings of hopelessness. Our findings are comparable with the results of another study [50]. However, no association was found between social circle and QoL among infertile females. But, Steuber et al. [51] report that women who are unable to disclose their infertility have poor QoL due to unmet social support.

Another finding of the present study was that males with a lower educational level had low QoL scores. This finding is in agreement with the findings of Jahromi et al. and Drozdzol et al., which highlight that infertile men with low or no academic education had lower QoL scores [11, 52].

The current study had several strengths and limitations. This is probably the first study to describe the association of QoL with resilience, depression, and other socio-demographic factors in infertile males and females at an infertility clinic. Moreover ACIMC in Karachi caters to diverse socio-economic and ethnic groups as patients are referred here from seven sub-branches of the Centre located in different provinces of Pakistan. Additionally the Trust at the centre caters to the needs of the non-affording, thus uplifting the generalizability of our study.. Contextual and reliable tools were used to assess QoL with resilience, depression, and other factors in infertile males and females.

However, the limitations of our study were that data on QoL and depression was collected using selfreporting tools; hence, the element of reporting bias could not be eliminated; though, special attention was given to ensure the privacy and confidentiality of the data collection process, to minimize this effect. Moreover, it was a single-centred study, hence, the results cannot be generalized to all infertile individuals residing in the communities and not utilizing any treatment, but it can be generalized to all private infertility clinics similar to our setting. In addition, we have not explored two important variables i.e. drug use/ abuse and other type of comorbidities such as endometriosis etc. so we cannot generalize our results on these women/men.

\section{Conclusion}

This study concluded that amongst infertile men QoL was negatively associated with no formal education, number of friends and depression; however, it had a positive association with income and resilience. Among females, QoL was associated with depression, resilience, and monthly income. Hence, future studies are required 
to explore the effectiveness of gender-specific mental health interventions, such as resilience building, to decrease depression and improve QoL among infertile individuals. Moreover, mental health experts, fertility experts, and other health care providers must be adequately trained to respond to the holistic needs of individuals going through fertility related problems.

\section{Abbreviations}

ACIMC: Australian Concept Infertility Medical Centre; LMIC: Low Middle Income Country; QoL: Quality of Life; AKU: Aga Khan University; ESHRE: European Society of Human Reproduction and Embryology; ASRM: American Society of Reproductive Medicine; SD: Standard Deviation; IQR: Inter quartile range

\section{Acknowledgements}

We acknowledge the cooperation of Dr. Gail Wagnild, CEO of the resilience centre, USA, for allowing us to use the resilience scale. We also appreciate the contribution of our data collectors, field coordinator, and the study participants.

\section{Authors' contributions \\ SSB contributed overall in the study, including project conceptualization, operationalization, data management, cleaning, analysis review, manuscript drafting, and reviewing. NZ helped in data cleaning, analysis, manuscript writing, and reviewing the paper. WZ contributed in the discussion section and in reviewing the paper. SF contributed in the introduction section and in reviewing the paper. SS contributed in the method section and in reviewing the paper. MC and NA contributed in reviewing the paper. All authors went through and approved the final version of the manuscript.}

\section{Authors' information}

SSB is a Public Health Nurse and currently doing her PhD from Ghent University, Belgium. She has completed her Masters in Epidemiology and Biostatistics and working as an Assistant Professor at Aga Khan University, School of Nursing and Midwifery. NZ is a doctor by profession and have years of experience in the field of embryology. She is currently enrolled as a PhD student in Uppsala university, Sweden and working as a Senior Instructor Research at Aga Khan University, Surgery Department. WZ is a dentist by profession and has completed her Masters in Epidemiology and Biostatistics, currently working as a Senior Instructor at Aga Khan University, Community Health Sciences Department. SF is a Mental Health Nurse by profession and currently serving as a Senior Instructor at Aga Khan University, School of Nursing and Midwifery. SS has completed her Masters in Nursing and is experienced as a Public Health Nurse. She is currently working as an Assistant Professor at Aga Khan University, School of Nursing and Midwifery. MC is a retired faculty from Vancouver Island University, she has an extensive experience as a Nurse Educator. NA is a psychologist by profession and has expertise in this field. She is currently at the position of Interim Dean of Aga Khan University, Psychiatry Department.

\section{Funding}

This research related work (data collection, data entry, field transportation of data collectors, stationary, data collection forms, photocopies, etc.) were supported by a Seed Grant (PF 89/1016) from the Aga Khan University. The funding agency had no role in the study design, data collection, data analysis, manuscript writing, or publication.

\section{Availability of data and materials}

The dataset used in current study is available from the corresponding author and can be released upon reasonable request.

\section{Ethics approval and consent to participate}

The Study was approved by Aga Khan University Ethical Review Committee (ERC \# 4615-SON-ERC 17) and written signed consent was obtained from the patients for data collection.

\section{Consent for publication}

Consent was obtained from the patients for data collection and for publishing the results, without disclosing their identity in any way.

\section{Competing interests}

All authors declare that there was no competing interest.

\section{Author details}

${ }^{1}$ School of Nursing and Midwifery, Aga Khan University, Karachi, Pakistan. ${ }^{2}$ Department of Surgery, Aga Khan University, Stadium Road, Karachi 74800, Pakistan. ${ }^{3}$ Community Health Sciences Department Aga Khan University, Karachi, Pakistan. ${ }^{4}$ Vancouver Island University, Vancouver, Canada.

${ }^{5}$ Department of Psychiatry, Aga Khan University, Karachi, Pakistan.

Received: 24 January 2020 Accepted: 14 October 2020

Published online: 23 October 2020

\section{References}

1. Tabong PT-N, Adongo PB. Infertility and childlessness: a qualitative study of the experiences of infertile couples in northern Ghana. BMC Pregnancy Childbirth. 2013;13(1):72.

2. Ombelet $W$, et al. Infertility and the provision of infertility medical services in developing countries. Hum Reprod Update. 2008;14(6):605-21.

3. Taniguchi $\mathrm{H}$, et al. Health-related quality of life in infertile couples receiving testicular sperm extraction treatment. Int J Urol. 2018;25(2):164-5.

4. Jisha P, Thomas I. Quality of life and infertility: influence of gender, years of marital life, resilience, and anxiety. Psychol Stud. 2016;61(3):159-69.

5. Begum BN, Hasan S. Psychological problems among women with infertility problem: a comparative study. J Pak Med Assoc. 2014;64(11):1287-91.

6. Rashidi B, et al. Health-related quality of life in infertile couples receiving IVF or ICSI treatment. BMC Health Serv Res. 2008;8(1):186.

7. Kumar N, Singh AK. Trends of male factor infertility, an important cause of infertility: a review of literature. J Hum Reprod Sci. 2015;8(4):191.

8. Zahid N, et al. Association of obesity with infertility among Pakistani men: a case control study. Open J Epidemiol. 2015;5(03):204.

9. Ramezanzadeh $\mathrm{F}$, et al. A survey of relationship between anxiety, depression and duration of infertility. BMC Womens Health. 2004;4(1):9.

10. Valsangkar $\mathrm{S}$, et al. An evaluation of the effect of infertility on marital, sexual satisfaction indices and health-related quality of life in women. J Hum Reprod Sci. 2011;4(2):80.

11. Jahromi BN, et al. Quality of life and its influencing factors of couples referred to an infertility center in Shiraz, Iran. Int J Fertil Steril. 2018;11(4):293.

12. Sami N, Saeed Ali T. Perceptions and experiences of women in Karachi, Pakistan regarding secondary infertility: results from a community-based qualitative study. Obstet Gynecol Int. 2012;2012(1):108756.

13. Ali $\mathrm{S}$, et al. Knowledge, perceptions and myths regarding infertility among selected adult population in Pakistan: a cross-sectional study. BMC Public Health. 2011;11(1):760.

14. Hasanpoor-Azghdy SB, Simbar M, Vedadhir A. The emotional-psychological consequences of infertility among infertile women seeking treatment: results of a qualitative study. Iran J Reprod Med. 2014;12(2):131.

15. Herrmann D, et al. Resilience in infertile couples acts as a protective factor against infertility-specific distress and impaired quality of life. J Assist Reprod Genet. 2011;28(11):1111-7.

16. Ranjbar $F$, et al. Experiences of infertile women seeking assisted pregnancy in Iran: a qualitative study. J Reprod Infertil. 2015;16(4):221.

17. Monga M, et al. Impact of infertility on quality of life, marital adjustment, and sexual function. Urology. 2004;63(1):126-30.

18. Group, W. The World Health Organization quality of life assessment (WHOQOL): position paper from the World Health Organization. Soc Sci Med. 1995;41(10):1403-9.

19. Lakatos $\mathrm{E}$, et al. Anxiety and depression among infertile women: a crosssectional survey from Hungary. BMC Womens Health. 2017;17(1):48.

20. Li Y, et al. Resilience acts as a moderator in the relationship between infertility-related stress and fertility quality of life among women with infertility: a cross-sectional study. Health Qual Life Outcomes. 2019;17(1):38.

21. Güleç $G$, et al. The effects of infertility on sexual functions and dyadic adjustment in couples that present for infertility treatment. Turk J Psychiatry. 2011;22(3):166-76.

22. Pujari S, Unisa S. Failing fatherhood: a study of childless men in rural Andhra Pradesh. Soc Secur Bull. 2014;63(1):21-40. 
23. Papreen $\mathrm{N}$, et al. Living with infertility: experiences among urban slum populations in Bangladesh. Reprod Health Matters. 2000;8(15):33-44.

24. Martínez-Martí ML, Ruch W. Character strengths predict resilience over and above positive affect, self-efficacy, optimism, social support, self-esteem, and life satisfaction. J Posit Psychol. 2017;12(2):110-9.

25. Bhamani SS, et al. Association of Depression and Life Satisfaction with low resilience among married women of Karachi, Pakistan. Open J Epidemiol. 2015;5(04):251.

26. Hashmi HA, Khurshid M, Hassan I. Marital adjustment, stress and depression among working and non-working married women. Internet J Med Update. 2007;2(1):19-26.

27. Hussain S. Psychiatric morbidity in infertile Pakistani women: a systematic review. J Pak Psych Soc. 2010;7:61-6.

28. Nelson CJ, et al. Prevalence and predictors of sexual problems, relationship stress, and depression in female partners of infertile couples. J Sex Med. 2008;5(8):1907-14.

29. Ramazanzadeh F, et al. Emotional adjustment in infertile couples. Int J Reprod BioMed. 2009;7(3):97-103.

30. Boivin J, Takefman J, Braverman A. The fertility quality of life (FertiQoL) tool: development and general psychometric properties. Fertil Steril. 2011;96(2): 409-15 e3.

31. Bhamani SS, et al. Validation of the Urdu version of Wagnild and Young's long and short resilience scales among 20-to 40-year-old married women living in urban squatter settlements of Karachi, Pakistan. J Nurs Meas. 2015 23(3):425-35.

32. Hirani SS, et al. Testing a community derived intervention to promote womenâ $€^{\mathrm{TM}} \mathrm{S}$ health: preliminary results of a 3-arm randomized controlled trial in Karachi. South Online J Nurs Res. 2010;10(3):1-10.

33. Dowrick $C$, et al. Resilience and depression: perspectives from primary care Health. 2008;12(4):439-52.

34. Alhassan A, Ziblim AR, Muntaka S. A survey on depression among infertile women in Ghana. BMC Womens Health. 2014;14(1):42.

35. Al-Abbudi SJR, Psych CB. Major depressive disorder association with unsuccessful in-vitro fertilization (IVF) of primary infertile women. Int J Contemp Res Rev. 2019;10(04):20717-25.

36. Rahmati $\mathrm{S}$, et al. Survey frequency of the depression and anxiety levels of infertile women in western Iran. Med J Indones. 2019;28(1):35-9.

37. Greil AL, Slauson-Blevins K, McQuillan J. The experience of infertility: a review of recent literature. Sociol Health III. 2010;32(1):140-62.

38. Namavar BJ, et al. Quality of life and its influencing factors of couples referred to an infertility Center in Shiraz, Iran. Int J Fertil Steril. 2018;11(4):293-7.

39. Ganth B, Thiyagarajan S, Nigesh K. Role of infertility, emotional intelligence and resilience on marital satisfaction among Indian couples. Int J Appl Psychol. 2013;3(3):31-7.

40. El Kissi Y, et al. General psychopathology, anxiety, depression and selfesteem in couples undergoing infertility treatment: a comparative study between men and women. Eur J Obstet Gynecol Reprod Biol. 2013;167(2): 185-9.

41. Chen $\mathrm{T}-\mathrm{H}$, et al. Prevalence of depressive and anxiety disorders in an assisted reproductive technique clinic. Hum Reprod. 2004;19(10):2313-8.

42. King RB. Subfecundity and anxiety in a nationally representative sample. Soc Sci Med. 2003;56(4):739-51.

43. Drosdzol A, Skrzypulec V. Depression and anxiety among polish infertile couples-an evaluative prevalence study. J Psychosom Obstet Gynecol. 2009; 30(1):11-20.

44. Chiaffarino F, et al. Prevalence and incidence of depressive and anxious symptoms in couples undergoing assisted reproductive treatment in an Italian infertility department. Eur J Obstet Gynecol Reprod Biol. 2011;158(2): 235-41

45. Sezgin H, Hocaoglu C, Guvendag-Guven ES. Disability, psychiatric symptoms, and quality of life in infertile women: a cross-sectional study in Turkey. Shanghai Arch Psychiatry. 2016;28(2):86.

46. Guz H, et al. Psychiatric symptoms in Turkish infertile women. J Psychosom Obstet Gynecol. 2003;24(4):267-71.

47. Namdar A, et al. Quality of life and general health of infertile women. Health Qual Life Outcomes. 2017:15(1):139.

48. Keramat A, et al. Quality of life and its related factors in infertile couples. J Res Health Sci. 2013;14(1):57-64.

49. Fisher JR, Hammarberg K. Psychological and social aspects of infertility in men: an overview of the evidence and implications for psychologically informed clinical care and future research. Asian J Androl. 2012;14(1):121.
50. Chachamovich J, et al. Congruence of quality of life among infertile men and women: findings from a couple-based study. Hum Reprod. 2009;24(9): 2151-7.

51. Steuber K, Solomon D. "So, when are you two having a baby?" Managing information about infertility within social networks. Peter Lang New York; 2011. p. 297.

52. Drosdzol A, Skrzypulec V. Quality of life and sexual functioning of polish infertile couples. Eur J Contracept Reprod Health Care. 2008;13(3):271-81.

\section{Publisher's Note}

Springer Nature remains neutral with regard to jurisdictional claims in published maps and institutional affiliations.
Ready to submit your research? Choose BMC and benefit from:

- fast, convenient online submission

- thorough peer review by experienced researchers in your field

- rapid publication on acceptance

- support for research data, including large and complex data types

- gold Open Access which fosters wider collaboration and increased citations

- maximum visibility for your research: over $100 \mathrm{M}$ website views per year

At $\mathrm{BMC}$, research is always in progress.

Learn more biomedcentral.com/submissions 